\title{
Analysis of Chongqing Agricultural Informatization Promoting Urban-rural Integration
}

\author{
Jiaju Cun \\ Department of Finance \\ Rongzhi College of Chongqing Technology \& \\ Business University \\ Chongqing, China \\ 240126053@qq.com
}

\author{
Xiaoyong Xu \\ School of Economics \& Management \\ Chongqing Normal University \\ Chongqing, China \\ 644527574@qq.com
}

\begin{abstract}
Agricultural informatization can narrow the gap of urban-rural informatization,the construction of its is an important measure of promoting urban-rural integration effectively. On the base of the current conditions of Chongqing agricultural informatization, this paper analyses the relationship between the construction agricultural informatization and urban-rural integration in Chongqing.lastly this paper provides some constructive suggestions to improve the rural agricultural informatization and promotes the process of urban-rural integration in Chongqing.
\end{abstract}

Keywords-agricultural informatization; urban-rural integration; information resources

\section{INTRODUCTION}

Since 1980s, the waves of agricultural informatization with the characteristics of computer, multi-media, communication technology arrives all over the world. So the agricultural informatization has become the standard of the national comprehensive competition. So does agriculture. The 16th National Party Congress greatly explicitly pointed out that agricultural information is the inevitable choice of our country to speed up the realization industrialization and the modernized inevitably. According to the standard of Euro-American countries, when a country information industry value-added in agriculture reaches the half of the agricultural total value, it becomes agricultural informatization into realization. The American agricultural informatization, namely $81.6 \%$, is higher than industrialization at present. However, the agricultural informatization is far belower industrization in China [1] .

Chongqing which locats in the western regions of China is a typical urban-rural "dual structure" city and bears the great historical mission of big city leading development of big village. Chongqing has got a series of supporting policies especially for integrating urban-rural development so as to promote development. In June, 2007, Chongqing and Chengdu were evaluated the comprehensive matching experimental zones for reform in China. For the time being, integrating urban-rural development has been promoted with planning step by step in whole city[2]. As we know that agricultural informatization is the strategy of rejuvenating the implementation and prospering rural market economy, promoting solving problems of "agriculture, countryside and farmers". So this paper focus on the study of the agricultural informatization promoting of urban-rural integration of Chongqing.

\section{THE CURRENT CONDITIONS OF CHONGQING AGRICULTURAL INFORMATIZATION}

With the development of network, Chongqing rural informatization has gone through projects "extend radio and TV coverage to every village" in the early years to the subsequent "information to the countryside" so that rural information technology has been application and popularization, and large-scale information infrastructure has been built gradually and exploited increasingly the agricultural information resources to promote rural economic development and raise farmers' income.

\section{A. Development of Information Industry}

China mobile base of "information to the countryside", and national internet of things industry demonstration base lie in Chongqing. Now in Chongqing, the biggest protablecomputer base in Asia has established and "Two river International Cloud Computing Center" is building now. So Chongqing is the important powerful service city of outsourcing soft and information in western regions in China.

\section{B. Improvement of the Information Infrastructur}

Chongqing Communication network are realized "information to the village", $100 \%$ towns and $80 \%$ administrative villages can phone among farmers (table 1) Remote education websites for rural Party leaders has built, in there 1003 town's information service stations, about 10700 terminal points of village-level sites. Mangy service telephone number of agriculture covered in the countryside, phone number 12396 for technology, phone number 12316 for agriculture, phone number 12582 and so on. independent document. Please do not revise any of the current designations.

Since 2001, Civil Affairs Department has adjusted the number of villages and towns, the number of villages gradually decreases, but Seen from table 1 the phone is popular in villages. 
TABLE I. PHONE HOUSEHOLDS AND VILLAGES IN CHONGQING COUNTRYSIDE

\begin{tabular}{|c|c|c|}
\hline year & $\begin{array}{c}\text { Phone households } \\
\text { countryside }\end{array}$ & $\begin{array}{c}\text { Villages with } \\
\text { phone }\end{array}$ \\
\hline 2007 & 26386000 & 8965 \\
\hline 2008 & 25300000 & 8947 \\
\hline 2009 & 22993000 & 8726 \\
\hline 2010 & 20630000 & 8686 \\
\hline 2011 & 18671000 & 8581 \\
\hline
\end{tabular}

Note: Data are from Chongqing Statistical Year book(2008-2012)

TABLE II. TVS AND COMPUTERS PER 100 HOUSEHOLDS BETWEEN CITY AND COUNTRYSIDE

\begin{tabular}{|c|c|c|c|c|}
\hline \multirow{2}{*}{ year } & \multicolumn{2}{|c|}{ TVS } & \multicolumn{2}{c|}{ Private Computers } \\
\cline { 2 - 5 } & City & Countryside & City & Countryside \\
\hline 2007 & 149.92 & 102.72 & 63.57 & 1.44 \\
\hline 2008 & 145.42 & 105.00 & 65.27 & 1.11 \\
\hline 2009 & 144.61 & 95.28 & 1.83 & 72.96 \\
\hline 2010 & 147.33 & 97.72 & 4.06 & 76.07 \\
\hline 2011 & 106.50 & 149.12 & 11.94 & 79.07 \\
\hline
\end{tabular}

Note: Data are from Chongqing Statistical Year book(2008-2012)
It can be seen from the table 1and 2 a family in village, town and city has about the same number of TVs, phones and TVs. That is, almost a family has a color TV, phone and telecommunication equipment is covered in countryside. Through the development of "Tri-network", there is an increase the number of Internet users using mobile broadband. According to the latest statistics of CNNIC, as of June 2010, the number of overall netizens reached 420 million, surpassing 400 million mark, increasing by 36 million compared with that at the end of 2009; the popularization rate of Internet climber to $31.8 \%$, increasing by $2.9 \%$ compared with that at the end of 2009.The application of Internet in rural areas is gradually deepened, and the demand for the Internet is growing. It can be seen from table 3 subject to low level of socio-economic development, inadequate Internet access, obsolete hardware and equipment and other factors, the number of Internet users in rural areas grows slowly, with rate lower than that of urban areas[3].

TABLE III. TVS AND COMPUTERS PER 100 HOUSEHOLDS BETWEEN CITY AND COUNTRYSIDE

\begin{tabular}{|c|c|c|c|c|c|c|c|c|}
\hline \multirow{2}{*}{ Time } & \multicolumn{2}{|c|}{ Region } & Mobile phone & \multicolumn{4}{c|}{ Occupation } \\
\cline { 2 - 10 } & Urban areas & Rural areas & Urban areas & Rural areas & Urban workers & Rural workers & Students & Others \\
\hline Dec.2009 & 72.2 & 27.8 & 69.2 & 30.8 & 55.7 & 2.8 & 28.8 & 12.7 \\
\hline Jun.. 2010 & 72.6 & 27.4 & 71.1 & 28.9 & 58.1 & 4.7 & 30.7 & 6.5 \\
\hline
\end{tabular}

\section{The scale of Database and Service Ssystem for Agriculture}

About 20 Characteristic industry information systems of "Precision management for oranges" and "information management for boar farm" are exploited in Chongqing, also, 50 related agricultural databases, "Soil database" "Terrain database" has been built. In addition, the national labor electronic business platform is open, the activities for labors on line has been started. Supply and marketing corporation general and mobile company has built 3000 agricultural chain stores of supply and marketing communication.

\section{The Improvement of Agricultural Service Ability}

The servers of remote education for party members in rural areas, correspondents of science and technology and grassroots agricultural technology servers totally 140000 persons make up the basic complementary rural information team in Chongqing. Chongqing information servicing mode ,e.g culture, the new type of rural cooperative medical care, new-countryside commercial internet, and supply and marketing communication, weather, disaster reduction and prevention, and targeted exploited information products, "agricultural paper", powerfully promote the popularity and application of rural information technology.

\section{E. Application of new Technological System in \\ Construction of Agricultural Informatization}

Internet of Things for agriculture is gradually empathized and developed widely in Chongqing. IOT intelligence perception technology and pervasive competing, ubiquitous network integration application is known as the third wave of the world's information industry the development computers, Internet and mobile communication. Chongqing Nan'an District has become the "National IOT Industry Demonstration Base". In March 2012, Chongqing government and Fonder Group began to establish IOT Industry Demonstration Base. At the same time, Chongqing Agricultural Station joint Tsinghua Tongfang launched the construction system of the Internet of things in China.

\section{THE PROBLEMS OF CHONGQING AGRICULTURAL INFORMATIZATION}

\section{A. Integration Agricultural Information Resources Inadequate}

With the years development of agricultural informatization, at present, the usage of Chongqing database, simulation system and so on as the representative of single technology in the field of agriculture is mature, network technology with the internet, telecommunication network and broadcast television network is also increasingly popular. View to the demands for information resources and technology comprehensively exploited and used, the single information technology and internet technology can't meet the users' needs. The issues on integration dispersed and dislocated rural information resoures, existing hardware resources and information resources and the function of multi-network are popular. 


\section{B. Improvement of Farmers' Information Ability}

In modern information times, farmers with information ability not only can watch TV, listen to radio and read paper but also can search and release information by means of networks[3]. Because most of the farmers cultural quality is low, their awareness of information is weak, and information ability is not strong., they don not realize the great effects of agricultural informatizaion and not active in the using of information.

\section{Scarcity of Talents of Information in Countryside}

Because talents of information in countryside can not be trained by government for the long time, the construction of agricultural team is lag, the demand of work can not satisfied by the personnel quantity, and service ability. The innovation for talents' capacity is insufficient. The structure and layout for talents isn't reasonable and human resources of talents can not be exploited fully. Scarcity of talents of information causes the construction and usage of agricultural informatizaion difficulty.

\section{THE RELATIONSHIP BETWEEN THE CONSTRUCTION AGRICULTURAL INFORMATIZATION AND URBAN-RURAL INTEGRATION IN CHONGQING IZATION}

\section{A. Agricultural Informatization Promotes City Capital Investment on Rural Industry}

The characteristic rural economic model "A village, A Brand" in Chongqing attracts city capital into countryside, so local government using the carriors of flower, fruit, seedling makes good use of local human geography and ecological tourism resources for promoting the third industry development. In 2009, the characteristic rural economic model "A village, A Brand" in Chongqing develops well, which attracts many persons from different fields especially university students and returned farmers to invest on it. According to the survey, there are about 130 rural inns in Wushan county in Chongqing.The capital of $60 \%$ of these inns are from city capital.

\section{B. Agricultural InformatizationCchangs theMmode of Production and Mmanagement}

In April 2012, Rongchang exchange trading center of Chongqing agricultural and livestock Center aucted 2529 piglets on line in China. With the help of nets resources, Rongchang exchange trading center of agricultural and livestock builds trans-time forward market. The platform came agricultural livestock, agricultural materials, industrial raw materials, bulk products into immediate, medium-term electronic trading on line. In January 2012, on the western agricultural fair Chongqing officially launched the marketing platform of agricultural goods on line. On the base platform of GIS geographic system, Chongqing orange industry with digital precession management system gives farmer households the functional services of orange distribution map, function, condition, planting and comments.

\section{Agricultural Informatization Proomtes Technolgical Application in Rural Areas}

With the development of Chongqing agricultural information demonstration projects, the first 4 demonstration districts and counties, 41 demonstration townships and town, 205 demonstration villages successfully have been approved. All demonstration websites, "A village, A Brand" characteristic rural products are in the internet, agricultural information service bus been into the farm household, remote diagnosis of video service terminal been into the village. Kiwi fruit advertised on the Gongyi Township, webpage of Wangzhou Distict attracts many merchants across the country to buy the fruit. Characteristic rural products advertised on the Fuling Webpage has 3 commercial intention contacts, the amount of the transaction reaches RMB 50000000. Villagers seeking experts' help by diagnosis system of video service overcomes the leaf curl disease for Crisp red plum.

\section{Agricultural Informatization Bridges Agricultural Products Market}

"Digital divide" especially outstands in Chongqing which blocks agricultural development, because of rural geographical dispersion, unbalanced development of regional economy, rural information transmission lag, asymmetric information, public information right to know is not be guaranteed. In recent years, Chongqing is dependent on the projects "Western Exploitment", "coordinate urbalrural development" to innovate agricultural information service means, widen the service field, strengthen the service contents meaningfully. In order to let farmers timely effectively know market information, and improve information service, Chongqing builds the "point to point", service model on line and builds 100000 key customers data to release information. The service model provides accurate market information to pig farmers in Banan and Changshou districts as to protect their benefits.

\section{E. Agricultural Informatization Pushes the Process of Industrization andUurbanization}

The farmers on Shaji town who make different simple furniture open Taobao shops in the internet and sell them to the cities. The new model of selling simple furniture on line makes Shaji town famous for its electronic commerce village in China. At the same time, it promotes abundently not only agricultural product processing industry development but also the upgrading of the industrial structure and electronic commercial development. The development of Shaji Towm not only overcomes local farmers' job problem but also attracts a large number of university graduates to entrepreneurship on Shaji Town. Agricultural development in countryside drives the flow of human resources rationally in cities and countryside and pushes the process of industrialization and urbanization. Chongqing can learn from the experience of "Shaji Town the mode of electronic commerce village" to speed up the process of industrialization and urbanization. 


\section{F. Agricultural Informatization Drives the ThirdIindustry Development in Rural Areas}

With the rapid development of informatization in society, popularity of internet and electronic commerce makes shopping fashionable on line. The leisure entertainment and various training consumption have gone a city to suburban village, then a variety of characteristics farm inns have been built. Characteristics farm innst in neighborhood of Chongqing sightseeing place and countryside drives local tourism culture industry development.

\section{G. Agricultural Informatization Promotes Rural Economy Development, Narrows the Gap Betwee Cities and Rural Areas}

Agricultural informatization is an important and effective means of promoting integrating urban-rural. In the process of agricultural informatization, application and popularization of agricultural informatization technology is benefit to narrow the gap between urban and rural areas. The popularization of intercommunication makes dissemination of information easier, especially marketing information and important agricultural knowledge. Rural industry development promotes agriculture industry development and optimazation, upgrading of the agricultural industrial structure and urban-rural integration process.

\section{CONCLUSIONS AND SUGGESTIONS}

\section{A. Conclusions}

1) Agricultural Informatization Promotes Chongqing Agriculture Modernization Development: In the process of agricultural informatization, the application of agricultural information technology and the popularization of modern agricultural knowledge upgrades the knowledge level and information literacy of farmers, which is benefit to improve the government decision-making level, promote the level of agricultural science and technology, promote the harmonious and sustainable development of agriculture.

2) Agricultural Informatization Raises Farmers' Income and Promotes Rural Economic Developmen:The basic means of rejuvenating rural economy and increasing farmers' income is to make agricultural products into market and sell out. To make sure effective connection between the farmers and the market, we must develop and facilitate the information technology and information resources. To realize the agricultural profit, farmers will ensure the scientific and accuracy of decision, being fully, timely, reliable transmission of information and information processing.

3) The Most Important Obstacle in the Agricultural Informatization Construction is the Talent: During the new period, talents become the most important factor of promoting agricultural informatization construction, so the government should establish the system of cultivation talents for agricultural information of multi-level, multi- channel to the well construction of agricultural informatization.

\section{B. Suggestions}

1) Improve the Network Construction to promote the Sharing of Information Resources: Giving full play to the role of existing media, rural radios,mobile phones, fixed phones,computers, Tvs and relying on the "Chongqing agricultural information network"of Chongqing agricultural affairs, science and technology websites been initially built, focus on the construction of agricultural product market system to implement agricultural industrialization, popularize advanced agricultural technology, develop agricultural science and technology, to provide wide effective information service. The effective agricutural policies, technology,market information are send to farmers and enterprises so as to make good use of information resouces .

2) Strengthen the Collection of Information to Expanse Agricultural Information:First, according to the demands of farmers and enterprises relative agriculture, the government actually takes an active action in collecting information, establishing rural information directory system and integrating relative agricultural resources, so as to guide users or professional talents to exploit and utilize information resources. Second, according to initially establishing "city-county-town-village" four-level information service system, Chongqing government cultivates four-level information acquisition team, makes good use of the comprehensive rural information service stations and correspondents' function to grasp the agricultural production tendency the whole city and counties. At the same time, Chongqing government builds relationship with China's agricultural websites by internet to share the local governmental resources, enrich and expanse agriculture information. Third, strengthen information analysis processing, deeply exploit and utilize resources to maximize it so as to ensure agricultural information network to provide a large number of farmers' demand useful information resources. At the same time, according to the farmers' demand, architect the "Fool" information system to let them know agricultural product market, master the latest agricultural production in a convennient and easy way.

3) Construct Standards and Technical Paltform to Promote Agricultural Informatization: Fusion the agricultural informatization internet system, websits and resources need standards and technical paltform support. Only in the technical platform of unified standard and specification, information resources can be compatible and shared, farmers acquire usefull information timely.

4) Construct Agriculture-related Enterprises of Hardware and Software to Improve Informatization: Farmers are active in agricultural informatization, promting farmer households popularizing and application of the 
agricultural information and technolgy. Agricultural enterprises shoud build their website and fuse into agricultural information internet to let cociety know them.Agricultural enterprises make the adventages of their information platfom to exploit agricultral information with relevant government departments and value-added service providers. That provides accurate information support for agricultural development and guarantees the increase of farmers' income.

5) Train Farmers through Different Ways to Improve Their Practical Skills: As for the training for rural information technology farmers, it should not be only the training for ability to use computer, and the ultimate goal of rural informatization is to train farmers to become educated, skilled, new farmers who are adept at operation, in order to provide sufficient human capital and new impetus for China's economic and social development, thus it is required to open farmers' mind and promote farmers' quality in a larger scale, at a higher level, and in more areas. Farmers use information technology infrastructure and information equipments, especially Chongqing existing agricultural information websites and e-goverment to improve the enthusiasm and initiative of the farmers to participate in the construction of agricultural informatization.

6) Strengthen Agricultural Information Technology Personnel Training: First, strengthen the construction of the team for grassroot agricultural correspondents. The goverment has a plan to cultivate agricultural information talents who not only use computer but also know agriculure and information technolgy to promote their ability of collection, analysis, collationa and releasing information. Second, use universities to train network utilization of related-agriculture information. Establish national agricultural information network education system and the local agricultural information education network system so as to realize the talents' rapid growth of different stages and areas. Third, cultivate innovative talents of science and technology. Train a number of complex, high-level talents knowing both information technology and the agriculture production management. Strengthen the introduction of agricultural information talents and overseas talents, and expanse the agricultural informatization professional team.

\section{ACKNOWLEDGMENT}

Supported by Science and Technology Project in Chongqing (KJ123101)

Supported by The National Social Science Fund (11XJL010)

\section{REFERENCES}

[1] Agricultural Statistics Service, "Farm computer usage and ownership," Washington: National Agricultural Statistics Service (NASS), Agricultural Statistics Board, U. S. Department of Agriculture, 2005:1-15.

[2] L. Deng, G.H Ran, J. li. The problems of coordinating urban-rural development of Chongqing city and corresponding measures of financial system. Asian agricultural research,Vol.3, pp109-115,2012.

[3] W. He, "Exploration of rural information and urban-rural information fusion,” Asian Agricultural Research, Vol. 4, pp 86-89, 2012. 